Asymmetric spillovers and sequential strategic investments

Jan Vandekerckhove and Raymond De Bondt

DEPARTMENT OF MANAGERIAL ECONOMICS, STRATEGY AND INNOVATION (MSI) 


\title{
ASYMMETRIC SPILLOVERS AND \\ SEQUENTIAL STRATEGIC INVESTMENTS
}

\author{
by \\ Jan Vandekerckhove ${ }^{*}$ \\ and \\ Raymond De Bondt*
}

February, 2007

Revised version of paper presented at The $1^{\text {st }}$ International Conference on Business and Management Research Facing $21^{\text {st }}$ Century Challenges, Bali, August $23^{\text {rd }}-24^{\text {th }}, 2006$.

*Jan Vandekerckhove

Catholic University of Leuven

Department of Managerial Economics, Innovation and Strategy

Naamsestraat 69

B - 3000 LEUVEN

Belgium

Phone: +32 16326904

Fax: +32 16326732

Jan.Vandekerckhove@econ.kuleuven.be
${ }^{* *}$ Raymond De Bondt

Catholic University of Leuven

Department of Managerial Economics, Innovation and Strategy

Naamsestraat 69

B - 3000 LEUVEN

Belgium

Phone: +3216326902

Fax: +3216326732

Raymond.DeBondt@econ.kuleuven.be 


\begin{abstract}
The focus of this paper is on the consequences of asymmetric spillovers on the strategic investments in an oligopoly with leaders and followers. Both in the investment and output game, leaders move before the followers. Spillovers may occur between leaders and between followers and from leaders to followers. The consequences are detailed for:

- $\quad$ the comparison of leader and follower efforts;

- the comparison of investments with or without cooperation of leaders, followers or leaders and followers;

- $\quad$ other specific real world situations.
\end{abstract}

It will be argued that there are critical levels of spillovers that drive the relevant tendencies. They tend to depend in a complex way on the other parameters of the oligopoly. Still some clear tendencies emerge that can help to understand asymmetric leader-follower rivalry.

Keywords: Strategic Investments, Sequential Game, Cooperation, Asymmetric Spillovers

J.E.L. Classification: D72, D43, L13

\title{
1. INTRODUCTION
}

Firms tend to be frequently involved in strategic investments in their attempt to achieve or maintain sustainable competitive advantages. Strategic investments may take many forms, such as expenditures to increase business and technological knowledge accumulation, advertising or service outlays to develop or maintain goodwill in the market, and investments directed at modifying product characteristics, production processes or features of the internal organization and/or the external institutional environment.

A number of the main characteristics of these investments are fairly well understood and are helpful in inspiring competitive analysis. Strategic investments, for example, tend to change the parameters of the market rivalry outcomes, they may hurt or benefit rivals and firms may have an incentive to temper or exaggerate efforts for strategic reasons. Some investments may involve special features. Asymmetric 
information between parties involved, knowledge spillovers and cooperation between some or all of the players involved, for example, will influence innovative strategic efforts in research and development.

In many cases strategic investments take place in an ongoing dynamic process. In some stages of this process some players will be leading and others will be following. The followers can observe earlier results and choices of leaders and the leaders may be able to anticipate how followers will react. It is known that this role playing affects the incentives and outcomes with, for example, innovative rivalry (Reinganum 1985; Doraszelski 2003; Etro 2004) and with capacity decisions through merger (Daughety 1990; Kamien and Zang 1990). This suggests that role playing is also likely to affect the incentives for and results of strategic efforts in oligopoly. In addition, asymmetric spillovers seem to be a more natural environment of industries characterized with several strategic groups, composed of dominant leading players and small fringe rivals.

The analysis of strategic investments in oligopoly received a burst from the study of a duopoly with simultaneous choices of cost-reducing investments with symmetric spillovers followed by a simultaneous choice of output (d'Aspremont and Jacquemin 1988; Kamien et al.; 1992). Several extensions emerged (a.o. De Bondt and Veugelers 1991; De Bondt and Wu 1997) and have been reviewed (De Bondt 1997; Sena 2004; Motta 2004). The analysis of asymmetric spillovers and role playing has only recently been touched upon in rather specific situations. Etro (2004) looks at one leader and many followers in a race setting with no attention to output rivalry and spillovers. De Bondt and Henriques (1995) and Amir et al. (2000) look at asymmetric spillovers and role playing in investments in a duopoly with simultaneous output decisions. Halmenschlager (2004) extends this setting to one leader and two followers, but only the latter make decisions on innovative investments while Atallah (2005) looks in detail at asymmetric spillovers but in a duopoly with simultaneous moves. Goel (1990) looks at only one Stackelberg leader investing and followers benefiting, and also Crampes and Langinier (2003) show in some specific settings the importance of extending this asymmetry to leader follower situations.

The incorporation of first and second movers raises a number of questions for the analysis. One needs to understand how such role playing comes about and evolves and what consequence this has for outcomes of interest, such as profits and consumer surplus. While progress has been made to explain for example 
price leadership, comparatively little has been done for leadership in other dimensions, such as technology and branding. With this in mind an attempt is made here to provide some parts of this puzzle. The intention here is to clarify the effects of asymmetric spillovers on the strategic investments of leaders and followers in oligopoly. Their existence will be taken as given, but their number will be allowed to vary so that the interaction of role playing and dimensions of rivalry can be studied. To fix ideas strategic investments will be equated with innovate efforts that lower unit costs or increase the choke price of a linear demand. Spillovers between leaders may differ from spillovers between followers and from spillovers between leaders and followers. If knowledge also spills from followers to leaders an industry with symmetric spillovers can be looked at. This will be done only to compare tendencies with existing symmetric settings.

Strategic innovative investments in a symmetric two stage oligopoly with simultaneous choices of investment followed by simultaneous choices of output have some clear characteristics. They tend to be lower or higher than cooperative efforts depending on whether or not the symmetric spillover is smaller or larger than a critical value. The impact of cooperation on firm profits, total output and static welfare are driven by the same critical value. The main point of this paper here is that this also applies in the more complicated setting of asymmetric spillovers with leaders and followers. Perhaps somewhat surprising a similar tendency drives the comparison of the leader and follower efforts. The critical spillovers, however, are typically, but not always, dependent on characteristics of the game played between leaders and followers.

Two settings will be considered: an "early entrance" setting with all firms investing before the output commitments and a "late entrance" setting with leaders choosing investment and output before the followers choose their investments and outputs. The first setting will be detailed somewhat more in detail and a later paragraph in the paper will detail differences that apply for the second setting. In a following section more details are given on the early entrance setting. In the subsequent sections results are provided on:

- the comparison of leader and follower efforts; 
- $\quad$ the comparison of investments with or without cooperation of leaders, followers or leaders and followers;

- $\quad$ other specific real world situations.

Implications for profit and static welfare will be provided as well.

\section{THE MODEL}

The focus is on an oligopoly market consisting of $n$ firms competing non-cooperatively on the output market with homogenous products. The model is an extension to sequential moves of earlier settings with simultaneous moves.

\subsection{Assumptions}

Of these $\mathrm{n}$ firms, $\mathrm{k}$ firms behave as leaders while the remaining $\mathrm{n}-\mathrm{k}$ firms are followers, both in the investment and in the output stage. The inverse demand function is:

$$
p=a-\sum_{i=1}^{k} q_{L, i}-\sum_{j=k+1}^{n} q_{F, j}
$$

with $\mathrm{i}=1, \ldots, \mathrm{k}$ and $\mathrm{j}=\mathrm{k}+1, \ldots, \mathrm{n}$. The choke price is a, $\sum_{i=1}^{k} q_{L, i}$ and $\sum_{j=k+1}^{n} q_{F, j}$ denote the total output of respectively the leaders (L) and the followers (F). Leaders and followers can commit to strategic investments, $x_{L, i}$ and $x_{F, j}$ in an attempt to maintain or improve the own competitive position. These commitments can take many forms, focused for example on branding, quality improvements or cost reductions. In most of the paper they will be equated with innovative investments, say in $R \& D$, that reduce unit costs. The discussion can also be applied to demand enhancing efforts that increase the parameter a.

A four stage game setting is considered. In an "early entrance" setting the sequence of play is as follows. In the first stage, all $k$ leaders decide on their strategic investment levels, knowing that each of the n-k followers will observe their efforts. In the second stage, followers decide on their commitments to innovative efforts. In the third stage, each leader commits to an output level, after observing the investments of the followers, and anticipating the subsequent output choices of the followers. In the final 
stage, followers decide on their output observing the results of the previous stages. The game is solved through backward induction.

Spillovers may occur in the investment stages one and two, between respectively the leaders and the followers. There may also be spillovers between the leaders in stage one and between the followers in stage two. This means that four groups of spillovers are looked at:

- $\quad$ leader-specific spillovers $\beta_{\mathrm{LL}}$;

- $\quad$ follower-specific spillovers $\beta_{\mathrm{FF}}$;

- $\quad$ spillovers from leaders to followers $\beta_{\mathrm{LF}}$

- $\quad$ spillovers from followers to leaders $\beta_{\mathrm{FL}}$.

\section{Insert Figure I}

All spillovers are given and symmetric in each category. Figure 1 explains the notation. The asymmetries are thus limited to possible differences between the four mentioned groups. The last group, spillovers from followers to leaders, is only used here to explain the consequences of overall symmetry $\left(\beta_{\mathrm{LL}}=\beta_{\mathrm{LF}}=\right.$ $\left.\beta_{\mathrm{FF}}=\beta_{\mathrm{FL}}=\beta\right)$. The discussions on asymmetries will be greatly simplified by setting this parameter $\beta_{\mathrm{FL}}=0$. This still captures a wide set of situations.

In modern market economies spillovers will depend on the type of strategic investments, as well as on the industry, the cultural, economic and legal environment. Some polar cases that will receive attention are:

- $\quad$ blue print diffusion: spillovers from leaders to followers $\beta_{\mathrm{LF}}=1$;

- $\quad$ idea diffusion: spillovers from leaders to followers $\beta_{\mathrm{LF}}=0$.

Many spillovers lie between these extremes that nevertheless are useful as benchmarks. The terminology serves as a metaphor and is borrowed from technology diffusion studies, where the wheel serves as an example of blue print diffusion, since it presumably was easy to copy just by looking at it. Other technologies such as the production of porcelain were reinvented around 1700 in Europe, given the 
Chinese examples from the $7^{\text {th }}$ century that reached the West in the $14^{\text {th }}$ century. The German follower chemists only knew for certain that it could be done and thus faced idea diffusion (Diamond 1997).

All firms enter stage 1 or 2 with an ex ante unit cost equal to c. The leaders enter stages three with an ex post unit cost $c_{\mathrm{L}, \mathrm{i}}$. The followers enter stage four with an ex post unit cost $\mathrm{c}_{\mathrm{F}, \mathrm{j}}$. Both ex post values are the difference between the ex ante unit costs and the amount of effective knowledge that the player has accumulated in the previous stages. The effective value is the sum of the own efforts and the imported knowledge from other firms that results from the spillovers. The ex post unit costs of leaders and followers are therefore given by the following equations (2) and (3):

$$
\begin{aligned}
& c_{L, i}=c-\left(x_{L, i}+\beta_{L L} \sum_{\substack{l=1 \\
l \neq i}}^{k} x_{L, l}+\beta_{F L} \sum_{f=k+1}^{n} x_{F, f}\right) \quad \mathrm{i}=1, \ldots, \mathrm{k} \\
& c_{F, j}=c-\left(x_{F, j}+\beta_{F F} \sum_{\substack{f=k+1 \\
f \neq j}}^{n} x_{F, f}+\beta_{L F} \sum_{l=1}^{k} x_{L, l}\right) \quad \mathrm{j}=\mathrm{k}+1, \ldots, \mathrm{n}
\end{aligned}
$$

with $c$ the ex ante unit costs of the leaders and the followers. On the basis of these ex post unit costs a Stackelberg equilibrium is obtained in stages 3 and 4. The equilibrium output levels depend, given (2) and (3), on the investments to be made in the earlier stages. These investments have for all firms a cost $\mathrm{g}(\mathrm{x})$ with diminishing returns:

$$
g(x)=\frac{\tau}{2} \times x^{2} \text { with } \tau \text { a given parameter and } \tau>0 .
$$

There is no discounting. Leaders and followers choose their efforts looking at profits:

$$
\begin{array}{ll}
\pi_{L, i}=\left(p-c_{L, i}\right) q_{L, i}-g\left(x_{L, i}\right) & \mathrm{i}=1, \ldots, \mathrm{k} \\
\pi_{F, j}=\left(p-c_{F, j}\right) q_{F, j}-g\left(x_{F, j}\right) & \mathrm{j}=\mathrm{k}+1, \ldots, \mathrm{n}
\end{array}
$$

with $\mathrm{q}_{\mathrm{L}, \mathrm{i}}$ and $\mathrm{q}_{\mathrm{F}, \mathrm{j}}$ the Stackelberg equilibrium values of the last stages. The followers choose their investments in stage 2 and the leaders choose in stage 1, knowing the effect on the rest of the game. 
When there are several leaders and several followers, cooperation among the leaders and/or among the followers can easily be introduced. Here only cooperation in the investment stages is looked at. In that case leaders in stage one, or followers in stage two, or both leaders and followers in respectively stage one and two, will look at the total profits of the cooperating players. In stage 3 and 4 they continue to play Stackelberg. Leaders may also choose investments independently à la Nash from other leaders, and likewise for the followers. So there are four games labelled A through D to be looked at. Table 1 summarizes the investment behaviour in these four possibilities.

Table 1. Four possibilities of investment behaviour of leaders and followers in respectively stage one and two. In all games a Stackelberg equilibrium in output is anticipated in the stages three and four.

\begin{tabular}{|c|c|c|}
\hline $\begin{array}{c}\text { Choice of } \\
\text { strategic }\end{array}$ & By leaders vis & By followers \\
investment in & à vis other & vis à vis other \\
followers \\
\hline Game A & leaders & Nash \\
\hline Game B & Nash & Nash \\
\hline Game C & Nash & Cooperation \\
\hline Game D & Cooperation & Cooperation \\
\hline
\end{tabular}

The solutions for the optimal investment levels and consequent output and profit levels of leaders and followers are rather complex. The analysis and results were therefore obtained by executing numerous numerical simulations with the mathematical software Maple. When possible, analytical solutions are presented ${ }^{1}$.

\footnotetext{
${ }^{1}$ With cooperating leaders (game B or game D), the investments of the leaders decrease with the outgoing spillover $\beta_{\mathrm{LF}}$. For high values of $\beta_{\mathrm{LF}}$ and low values of $\beta_{\mathrm{LL}}$, the solutions can yield negative investments of the leaders, which are impossible. It is then assumed that the leaders do no invest at all $\left(\mathrm{x}_{\mathrm{L}}=0\right)$.
} 
Table 2. Impact of spillovers on investments of leaders and followers, and on the investment gap G $\left(\mathrm{G}=\mathrm{x}_{\mathrm{L}}-\mathrm{x}_{\mathrm{F}}\right)$.

\begin{tabular}{|c|c|c|c|c|c|c|c|c|c|}
\hline Game & $\partial \mathrm{x}_{\mathrm{L}} / \partial \beta_{\mathrm{LF}}$ & $\partial x_{F} / \partial \beta_{L F}$ & $\partial \mathrm{G} / \partial \beta_{\mathrm{LF}}$ & $\partial \mathrm{x}_{\mathrm{L}} / \partial \beta_{\mathrm{LL}}$ & $\partial \mathrm{x}_{\mathrm{F}} / \partial \beta_{\mathrm{LL}}$ & $\partial \mathrm{G} / \partial \beta_{\mathrm{LI}}$ & $\partial x_{L} / \partial \beta_{F F}$ & $\partial \mathrm{x}_{\mathrm{F}} / \partial \beta_{\mathrm{FF}}$ & $\partial \mathrm{G} / \partial \beta_{\mathrm{FF}}$ \\
\hline A & \multirow{4}{*}{$<0$} & \multirow{4}{*}{$<>0$} & \multirow{4}{*}{$<0$} & $<0$ & \multirow{4}{*}{$<>0$} & $<0$ & \multirow{4}{*}{$<>0$} & $<0$ & \multirow[t]{2}{*}{$>0$} \\
\hline B & & & & $>0$ & & $>0$ & & $<0$ & \\
\hline $\mathrm{C}$ & & & & $<0$ & & $<0$ & & $>0$ & $>0$ \\
\hline D & & & & $>0$ & & $>0$ & & $>0$ & \\
\hline
\end{tabular}

Table 3. Impact of number of rivals $\mathrm{n}$ and number of leaders $\mathrm{k}$ on investments of leaders and followers with selected values of spillovers.

\begin{tabular}{|c|c|c|c|c|}
\hline Game & $\partial \mathrm{x}_{\mathrm{L}} / \partial \mathrm{n}$ & $\partial \mathrm{x}_{\mathrm{L}} / \partial \mathrm{k}$ & $\partial \mathrm{x}_{\mathrm{F}} / \partial \mathrm{n}$ & $\partial \mathrm{x}_{\mathrm{F}} / \partial \mathrm{k}$ \\
\hline A & \multirow{4}{*}{$\begin{array}{l}\beta_{\mathrm{LF}}=0:>0 \\
\beta_{\mathrm{LF}}=1:<0\end{array}$} & $<0$ & & \multirow{4}{*}{$<0$} \\
\hline B & & $\begin{array}{l}\beta_{\mathrm{LF}}=0:<0 \\
\beta_{\mathrm{LF}}=1:>0\end{array}$ & $<0$ & \\
\hline $\bar{C}$ & & $<0$ & \multirow{2}{*}{$\begin{array}{l}\beta_{\mathrm{FF}}=0:<0 \\
\beta_{\mathrm{FF}}=1:>0\end{array}$} & \\
\hline$\overline{\mathrm{D}}$ & & $\begin{array}{l}\beta_{\mathrm{LF}}=0:<0 \\
\beta_{\mathrm{LF}}=1:>0\end{array}$ & & \\
\hline
\end{tabular}

${ }^{\circ}$ : k small

\subsection{Some tendencies}

The strategic investments of leaders and followers are affected by spillovers and rivalry. Important tendencies on spillover effects are reported in Table 2. Table 3 details the effects of changes in the number of rivals or leaders. The spillovers from leaders to followers tend to discourage the leader efforts 
both when they are competing and cooperating with other leaders. The effect of $\beta_{\mathrm{LF}}$ on the incentives of the followers can be either positive or negative but is always very small. The difference between leader and follower efforts will tend to decrease as well. These are familiar tendencies resulting from the change in appropriability. The effects of larger spillovers within a group are that they discourage own efforts when competing and stimulate when cooperating. The effect on the investments of the other group is ambiguous (but small).

A given number of leaders are discouraged by more followers (larger $n$ ) with blue print diffusion. With idea diffusion they are stimulated. Followers will in both cases be discouraged if their in-group spillovers are large. More leaders for a given number of rivals will discourage competing leaders, as well as cooperating leaders with idea diffusion. Or in other words, more followers with competition will stimulate leaders. This familiar tendency has also been empirically detected by Ceccagnoli (2005). Cooperating leaders with blue print diffusion may be stimulated. Competing followers with no in-group spillovers are discouraged by more leaders. If they cooperate they will increase efforts in response to the efforts of more leaders.

\section{IMPACT OF LEADING OR FOLLOWING}

It is well known that incumbent established firms often fail to remain technological leaders. A number of factors can contribute to the tendency for innovative performance to slow down, related to for example the fear of cannibalization, the sunk nature of existing technology and the inappropriate internal organisation of the evaluation and the operation of new innovative ventures. Economists have detected in racing and other models the disincentives caused by high current profits and have called this the replacement effect. In many markets with vertical differentiation, buyers will tend to focus on the best quality and will leave even slightly lower quality versions. Newcomers may not be inhibited by a desire to protect current success, and have strong incentives to engage in larger efforts to introduce superior imitations that hurt leaders' profits. Empirical tendencies in some very large samples have detected that the lower efforts of the incumbent and the larger efforts of the challengers seem to prevail on average (Czarnitzki and Kraft 2004). In some markets all of this may result in so called technological leapfrogging, as has been detailed for video game console industry (Schilling 2003). Followers that surpass pioneers may also be involved in more intensive innovative efforts for a variety of reasons, 
including second mover advantages (Schnaars 1994). But perhaps the rivalry that is modelled here also provides incentives that support these tendencies.

These tendencies are somewhat complicated but do suggest that it may be possible to extract some results on the comparison of leader and follower efforts. This comparison is driven by the magnitude of the outgoing spillover $\beta_{\mathrm{LF}}$, see the Appendix. Results of numerical simulations available from the authors provide the following:

In case spillovers are symmetric competing leaders will tend to invest more than competing followers. A limited number of followers may invest more only when leaders are cooperating and spillovers are low.

Result (7) is consistent with tendencies of competing leading firms to use different strategies and business models than smaller fringe firms in industries with low spillovers. In the beer sector, for example, large multinational players focus on global advertising intensive branding, while smaller ones relay on local specialized beer with little or no advertising efforts. Spillovers of goodwill and specific knowledge from one player to the other tend to be rather low in all categories and thus a low symmetric spillover scenario applies. Only when leaders were then to cooperate they would limit their strategic investments. Followers would then increase their efforts, provided there are not too many of them. A similar argument could be made for high tech industries with symmetric high information flow between all players. Sharper differences are detected with asymmetric spillovers:

With asymmetric spillovers leaders will tend to invest more than followers if the spillover from leaders to followers is sufficiently small.

A follower may also invest more than a leader. With leaders competing this is more likely to happen with:

- $\quad$ blue print diffusion to followers and other leaders $\left(\beta_{\mathrm{LF}}=\beta_{\mathrm{LL}}=1\right)$;

- $\quad$ or cooperating followers with a high internal spillover.

With leaders cooperating this is more likely to happen with:

- $\quad$ blue print diffusion to followers $\left(\beta_{\mathrm{LF}}=1\right)$

- $\quad$ or cooperating followers with high internal spillovers. 
If there is only one leader and one follower and blue print diffusion, the model predicts that the follower may invest more than the leader. This then corresponds to the familiar case of an imitator surpassing a pioneer. In the pharmaceutical industry, for example, blue print diffusion could correspond to one firm having a patent on a new drug. The patent may give all the information about the chemical avenues to pursue and inventing around may be stimulated. In 1954 Hoffman-La Roche knew that a competitor had a pill to calm down agitated people. It went on to order extensive pharmaceutical testing that culminated in Librium in 1960 and in Valium in 1963 (The Economist (15 October 2005)). Etro (2004) reports a similar reversal of tendencies from the number of followers in a Stackelberg racing setting.

\section{IMPACT OF COOPERATION}

The players may also engage in cooperation within each group when choosing the strategic investment levels. In game B the leaders cooperate and followers compete, while in game $\mathrm{C}$ followers cooperate and leaders compete. In game D both leaders and followers cooperate. In all cases they continue to play Stackelberg in the output stages. First the symmetric case is looked at.

\subsection{Symmetric spillovers}

With symmetry the tendencies are clear, see Appendix:

Cooperation among leaders results in higher (lower) efforts than with competition if and only if the symmetric spillover $\beta$ is larger (smaller) than $\beta^{\mathrm{LC}}=[(\mathrm{n}-\mathrm{k}+1) /(\mathrm{n}-\mathrm{k}+2)]$.

Cooperation among followers results in higher (lower) efforts than with competition if and only if the symmetric spillover $\beta$ is larger (smaller) than $\beta^{\mathrm{FC}}=1 / 2$.

Cooperation hereby results in higher firm profits except for razor edge cases. For $\beta=\beta^{\mathrm{LC}}$ leader profits do not change compared to competition and for $\beta=\beta^{\mathrm{FC}}$ the follower profits do not change compared to when they are competing. The critical spillover $\beta^{\mathrm{LC}}$ does not depend on the followers competing or cooperating. It equals $1 / 2$ if all firms are leading. In that case all members choose simultaneously their effort levels. 
Likewise is the value of $1 / 2$ in (10) not a function of leaders cooperating or competing. Since $\partial \beta^{\mathrm{LC}} / \partial \mathrm{n}>0$ and $\partial \beta^{\mathrm{LC}} / \partial \mathrm{k}<0$, it follows:

As entry occurs with a given number of leaders, cooperation among leaders needs a higher symmetric spillover to render their efforts higher than with competition.

With more leaders and a given number of rivals, cooperation among leaders needs smaller a smaller symmetric spillover to render their effort higher than with competition.

These are generalisations of the findings in the two stage models with simultaneous choices of investment. So joint ventures among a few leading firms in order to increase innovative efforts are most likely to occur in industries with very high spillovers.

\subsection{Asymmetric spillovers}

With asymmetric spillovers the comparisons are again driven by critical spillover, see Appendix. This allows to state:

Cooperation among leaders with $\beta_{\mathrm{FL}}=0$ results in higher (lower) efforts than with competition if and only if the spillover $\beta_{\mathrm{LL}}$ among the leaders is larger (smaller) than $\beta_{\mathrm{LL}}{ }^{\mathrm{C}}$.

Cooperation among followers with $\beta_{\mathrm{FL}}=0$ results in higher (lower) efforts with competition if and only if the spillover $\beta_{\mathrm{FF}}$ among the followers is larger (smaller) than $\beta_{\mathrm{FF}}{ }^{\mathrm{C}}=1 /\left[2+(\mathrm{n}+1) \mathrm{k}-\mathrm{k}^{2}\right]$.

The conclusions concerning the impact of cooperation on the profitability of leaders and followers are the same as with symmetric spillovers. Cooperation increases profits except in the razor edge cases with the critical spillovers. 
The critical value $\beta_{\mathrm{LL}}{ }^{\mathrm{C}}$ depends in a complicated way on the other parameters of the model. The value is moreover different for followers competing or cooperating. In both cases numerical simulations indicate that typically $\partial \beta_{\mathrm{LL}} \mathrm{C} / \partial \mathrm{k}>0$ for $\beta_{\mathrm{LF}}=0$ and $\partial \beta_{\mathrm{LL}}{ }^{\mathrm{C}} / \partial \mathrm{k}<0$ for $\beta_{\mathrm{LF}}=1$. Differentiation also reveals that $\partial \beta_{\mathrm{FF}}^{\mathrm{C}} / \partial \mathrm{n}<0$ and sign $\partial \beta_{\mathrm{FF}}^{\mathrm{C}} / \partial \mathrm{k}=\operatorname{sign}[2 \mathrm{k}-(1+\mathrm{n})]$. Combining this with numerical tendencies allows stating that with $\beta_{\mathrm{FL}}=0$ :

With blue print diffusion $\left(\beta_{\mathrm{LF}}=1\right)$ : cooperation of leaders need a high minimum $\beta_{\mathrm{LL}}$ to stimulate their efforts compared to competition; the minimum $\beta_{\mathrm{LL}}$ tends to decrease as the number of leaders increases.

With idea diffusion $\left(\beta_{\mathrm{LF}}=0\right)$ : cooperation of leaders need a lower minimum $\beta_{\mathrm{LL}}$ to stimulate their efforts compared to competition; the minimum $\beta_{\mathrm{LL}}$ tends to increase as the number of leaders increases.

Cooperation of followers needs a lower minimum $\beta_{\mathrm{FF}}$ to stimulate their efforts compared to when they are competing, as the number of rivals increase or as a small number of leaders $(\mathrm{k}<(1+\mathrm{n}) / 2)$ increase.

The tendencies can be understood with the aid of Table 2 and 3. Blueprint diffusion, for example, discourage innovative efforts of both competing or cooperating leaders. But more leaders stimulate individual cooperative efforts. In industries with more leaders they need a smaller specific spillover to render their cooperative effort larger than with competition among the leaders.

\section{IMPLICATIONS FOR STATIC WELFARE}

Static welfare is here defined as the sum of consumer's and producer's surplus. The question is whether cooperation has a positive or negative impact on this measure. With symmetric spillovers welfare with cooperation is higher than with competition if and only if it cooperation results in higher strategic investment efforts. Again the symmetric benchmark case is reported first. 


\subsection{Symmetric spillovers}

With the propositions detailed in the Appendix a ranking emerges, see Table 3. With low symmetric spillovers competition (A) is best and all players cooperating within their group (D) is worst. Given intermediate spillovers cooperation of only followers is best (C) and cooperation of only leaders (B) is worst. With high spillovers cooperation of leaders and followers in their group is best (D) and all competing is worst (A). Cooperation of only leaders (B) is then better. But only leaders cooperating is not such a good idea for static welfare in case spillovers are intermediate.

\section{Insert Figure II}

\subsection{Asymmetric spillovers}

When spillovers are asymmetric, cooperation among the leaders can again result in higher or lower social welfare, dependent on the level of the leader or follower specific spillovers. Table 4 provides typical tendencies that are congruent with the symmetric case.

Table 4. Comparison of static welfare for leader follower games with symmetric and asymmetric spillovers. The four games involve: $\mathrm{A}=(\mathrm{NL}, \mathrm{NF}), \mathrm{B}=(\mathrm{CL}, \mathrm{NF}), \mathrm{C}=(\mathrm{NL}, \mathrm{CF})$ and $\mathrm{D}=(\mathrm{CL}$, $\mathrm{CF}$ ), with $\mathrm{N}=$ Nash, $\mathrm{C}=$ cooperation, $\mathrm{L}=$ leaders, $\mathrm{F}=$ followers.

\begin{tabular}{|c|c|c|}
\hline Symmetric spillover $\beta\left(^{*}\right)$ & $\begin{array}{c}\text { Asymmetric spillovers, } \\
0<\beta_{\mathrm{FF}}{ }^{\mathrm{C}}<\beta_{\mathrm{FF}}{ }^{*}<\beta_{\mathrm{LL}}{ }^{\mathrm{C}}<1\left(^{\circ}\right)\end{array}$ & $\begin{array}{c}\text { Ranking static welfare } \\
\text { in games A, B, C and D }\end{array}$ \\
\hline Small: & "Small": \\
$\beta^{*} \leq \beta<0,5$ & $\beta_{\mathrm{FF}}{ }^{\mathrm{C}}<\beta_{\mathrm{FF}}<\beta_{\mathrm{FF}}{ }^{*}$ \\
$\beta_{\mathrm{FF}}{ }^{\mathrm{C}} \leq \beta_{\mathrm{LL}}<\beta_{\mathrm{FF}}{ }^{*}$ & $\mathrm{~A}>\mathrm{C}>\mathrm{B}>\mathrm{D}$ \\
\hline Intermediate: & Intermediate: \\
$0,5<\beta<(\mathrm{n}-\mathrm{k}+1) /(\mathrm{n}-$ & $\beta_{\mathrm{FF}}{ }^{*}<\beta_{\mathrm{FF}}<\beta_{\mathrm{LL}}{ }^{\mathrm{C}}$ & $\mathrm{C}>\mathrm{A}>\mathrm{B}$ \\
$\mathrm{k}+2)$ & $\beta_{\mathrm{FF}}{ }^{*}<\beta_{\mathrm{LL}}<\beta_{\mathrm{LL}}{ }^{\mathrm{C}}$ & $\mathrm{C}>\mathrm{D}>\mathrm{B}$ \\
\hline Large: & ${ }^{\mathrm{Large}:}$ & $\mathrm{D}>\mathrm{C}>\mathrm{B}>\mathrm{A}$ \\
$(\mathrm{n}-\mathrm{k}+1) /(\mathrm{n}-\mathrm{k}+2)<\beta \leq 1$ & $\beta_{\mathrm{LL}}{ }^{\mathrm{C}}<\beta_{\mathrm{FF}} \leq 1$ & \\
& $\beta_{\mathrm{LL}}{ }^{\mathrm{C}}<\beta_{\mathrm{LL}} \leq 1$ & \\
\hline
\end{tabular}


*: When spillovers are very low $\left(0<\beta<\beta^{*}\right), \mathrm{C}>\mathrm{A}>\mathrm{D}>\mathrm{B}$. The values of $\beta^{*}$ are very close to 0 .

${ }^{\circ}$ : Results for very small values of $\beta_{\mathrm{FF}}<\beta_{\mathrm{FF}}^{\mathrm{C}}$ without cooperation of followers are $\mathrm{A}>\mathrm{B}$.

With large spillovers between followers and leaders cooperation (D) is the best for static welfare. This tendency also applies in the two symmetric stage settings with simultaneous moves in investments and output (Kamien et al. 1992)). The results of (15) to (17) can now be used to further evaluate what small, intermediate and large spillovers are. With blue print diffusion leader spillovers are more likely to fall in the small or intermediate category. With idea diffusion the larger spillover categories become more likely. The impact of the number of leaders can also be detected.

\section{SPECIFIC SITUATIONS}

The model can also be used to sharpen insights into specific competitive situations. To illustrate, the effects of spillovers between leaders on the one hand and of idea versus blue print diffusion on the other hand are looked at in all games.

\subsection{Spillovers between leaders}

Suppose there is an industry with two leaders and a number of followers ${ }^{2}$ :

- $\quad$ leaders benefit from idea diffusion: $\beta_{\mathrm{LF}}=0$;

- $\quad$ there is no feedback from fringe to leaders: $\beta_{\mathrm{FL}}=0$;

- $\quad$ followers do not share useful information: $\beta_{\mathrm{FF}}=0$;

- $\quad$ leaders work with no or with large spillovers: $\beta_{\mathrm{LL}}=0$ or $\beta_{\mathrm{LL}}=1$.

Table 5 indicates the choices and outcomes based on numerical simulations.

So consistent with symmetry, large spillovers among competing leaders (A and C) is discouraging their efforts, although their profits are better. Because of the high spillovers between the competing leaders,

\footnotetext{
${ }^{2}$ The results here are based on numerical simulations with $\mathrm{n}=10$ and $\mathrm{k}=2$.
} 
their effective knowledge $\mathrm{X}$ is higher with fully shared information. This variable, called $\mathrm{X}$, is equal to the own effort plus the spillover $\beta_{\mathrm{LL}}$ times the efforts of the other leader. But for followers this is the reverse. When leaders cooperate (B and D), high leader-specific spillovers have a positive impact on their efforts. Followers tend to reduce their R\&D efforts (and also trivially their effective efforts) when leaders

Table 5. Investment $x$, effective knowledge $X$, consumer surplus CS, firm profits $\pi$, producer surplus PS and static welfare $\mathrm{W}=\mathrm{CS}+\mathrm{PS}$. Comparison for $\beta_{\mathrm{LL}}=0$ and 1 , with $\beta_{\mathrm{FF}}=\beta_{\mathrm{LF}}=\beta_{\mathrm{FL}}=0$ for games A, B, C and D.

\begin{tabular}{|c|c|c|c|c|c|c|c|c|}
\hline \multirow[b]{2}{*}{$\beta_{\mathrm{LL}}$} & \multicolumn{2}{|c|}{ Game A } & \multicolumn{2}{|c|}{ Game B } & \multicolumn{2}{|c|}{ Game C } & \multicolumn{2}{|c|}{ Game D } \\
\hline & 0 & 1 & 0 & 1 & 0 & 1 & 0 & 1 \\
\hline $\mathrm{x}_{\mathrm{L}}$ & & $>$ & & $<$ & & $>$ & & $<$ \\
\hline $\mathrm{X}_{\mathrm{F}}$ & & $>$ & & $>$ & & $>$ & & $>$ \\
\hline$X_{L}$ & & $<$ & & $<$ & & $<$ & & $<$ \\
\hline$X_{F}$ & & $>$ & & $>$ & & $>$ & & $>$ \\
\hline $\mathrm{CS}$ & & $<$ & & $<$ & & $<$ & & $<$ \\
\hline$\pi_{\mathrm{L}}$ & & $<$ & & $<$ & & $<$ & & $<$ \\
\hline$\pi_{\mathrm{F}}$ & & $>$ & & $>$ & & $>$ & & $>$ \\
\hline PS & & $<$ & & $>$ & & $<$ & & $>$ \\
\hline W & & $<$ & & $<$ & & $<$ & & $<$ \\
\hline
\end{tabular}

fully share information, although this difference is rather small. In fact, most of these results follow logically from table 2 and section 2.2. Followers perform always worse when leaders have large group specific spillovers. Furthermore, consumer surplus (total industry output), total profits and static welfare are higher with high spillovers between the leaders.

\subsection{Idea versus blue print diffusion}


Suppose an industry with $\mathrm{k}$ leaders and $\mathrm{n}-\mathrm{k}$ followers:

- $\quad$ the number of leaders is small $(\mathrm{k} \leq \mathrm{n} / 2)$;

- $\quad$ there is no feedback from fringe to leaders: $\beta_{\mathrm{FL}}=0$;

- $\quad$ followers do not share useful information: $\beta_{\mathrm{FF}}=0$;

- $\quad$ leaders work with no or with large spillovers: $\beta_{\mathrm{LL}}=0$ or $\beta_{\mathrm{LL}}=1$;

- $\quad$ there is idea or blue print diffusion: $\beta_{\mathrm{LF}}=0$ or $\beta_{\mathrm{LF}}=1$.

Table 6. Investment $\mathrm{x}$, effective knowledge $\mathrm{X}$, consumer surplus $\mathrm{CS}$, firm profits $\pi$, producer surplus PS and static welfare $\mathrm{W}=\mathrm{CS}+\mathrm{PS}$. Comparison for $\beta_{\mathrm{LF}}=0$ and 1 , with $\beta_{\mathrm{FF}}=\beta_{\mathrm{FL}}=\beta_{\mathrm{LL}}=0$ for games A, B, C and D.

\begin{tabular}{|c|c|c|c|c|c|c|c|c|}
\hline \multirow[b]{2}{*}{$\beta_{L L}$} & \multicolumn{2}{|c|}{ Game A } & \multicolumn{2}{|c|}{ Game B } & \multicolumn{2}{|c|}{ Game $\mathrm{C}$} & \multicolumn{2}{|c|}{ Game D } \\
\hline & 0 & 1 & 0 & 1 & 0 & 1 & 0 & 1 \\
\hline $\mathrm{x}_{\mathrm{L}}$ & & $>$ & & $>$ & & $>$ & & $>$ \\
\hline $\mathrm{X}_{\mathrm{F}}$ & & $>$ & & $<$ & & $<$ & & $<$ \\
\hline $\mathrm{X}_{\mathrm{L}}$ & & $>$ & & $>$ & & $>$ & & $>$ \\
\hline $\mathrm{X}_{\mathrm{F}}$ & & $<$ & & $<$ & & $<$ & & $<$ \\
\hline $\mathrm{CS}$ & & $<$ & & $>$ & & $<$ & & $>$ \\
\hline$\pi_{\mathrm{L}}$ & & $>$ & & $>$ & & $>$ & & $>$ \\
\hline$\pi_{\mathrm{F}}$ & & $>$ & & $<$ & & $<$ & & $<$ \\
\hline PS & & $<$ & & $<$ & & $<$ & & $<$ \\
\hline W & & $<$ & & $>$ & & $<$ & & $>$ \\
\hline
\end{tabular}

Tables 6 and 7 indicate the choices and outcomes based on numerical simulations. In case that competing leaders (A and C) share little knowledge, consumers are better off with blue print diffusion, see Table 6. The followers also like to see this high spillover, as it increases their profits. But leaders are hurt by this 
free riding of imitators. The positive effect on the profits of the followers dominates, and producer surplus is higher with blue print diffusion. So if competing leaders are working with independent technologies and little spillovers, society is better off with broad diffusion.

Table 7. Investment $\mathrm{x}$, effective knowledge $\mathrm{X}$, consumer surplus CS, firm profits $\pi$, producer surplus PS and static welfare $\mathrm{W}=\mathrm{CS}+\mathrm{PS}$. Comparison for $\beta_{\mathrm{LF}}=0$ and 1 , with $\beta_{\mathrm{FF}}=\beta_{\mathrm{FL}}=0$ and $=\beta_{\mathrm{LL}}=1$ for games $\mathrm{A}, \mathrm{B}, \mathrm{C}$ and $\mathrm{D}$.

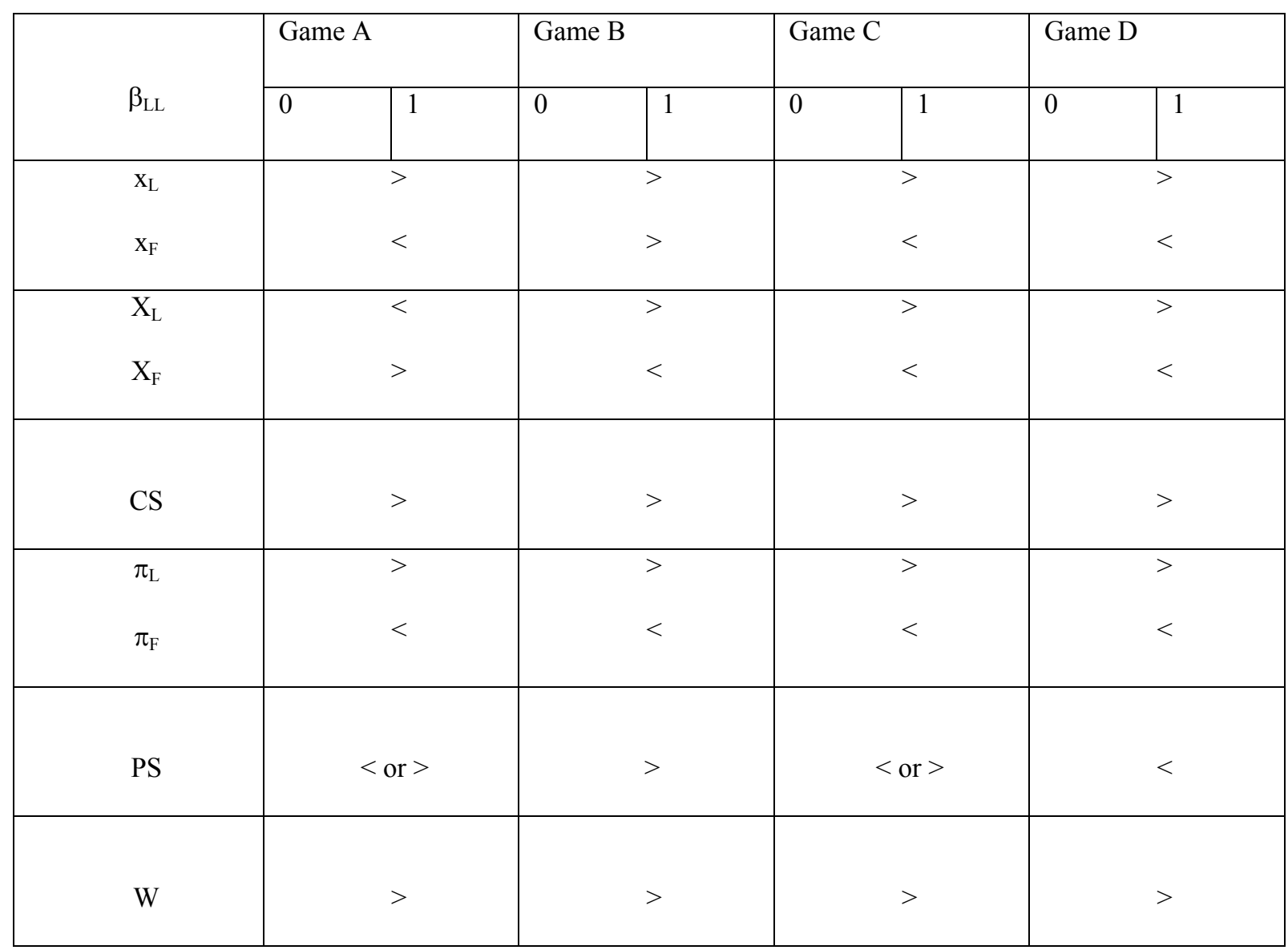

However, when leaders cooperate (B and D) but do not share R\&D results, see table 6, some of the welfare effects are reversed. After all, consumers prefer idea diffusion $\left(\beta_{\mathrm{LF}}=0\right)$. However, producer surplus is still higher with blue print $\left(\beta_{\mathrm{LF}}=1\right)$. In total, social welfare is higher when there exists a kind of a firewall $\left(\beta_{\mathrm{LF}}=0\right)$ between first and second movers when the leaders cooperate. 
When leaders work with related technologies and benefit from high spillovers from each other $\left(\beta_{\mathrm{LL}}=1\right)$, consumers would like to see a firewall between leaders and followers in all games (see table 7). Also leaders prefer only idea diffusion. The followers, on the contrary, still prefer blue print diffusion. This also improves total industry profits ${ }^{3}$. The effect of the consumer surplus dominates, however, and static welfare is always higher with idea diffusion. So followers will argue for blue print diffusion, leaders will oppose it. The government should follow the leaders. The previous tendencies need to be adapted if the number of leaders is large.

\section{LATE ENTRANCE MODEL}

A related, but slightly different, model is the late entrance model. This game also exists of four stages, but their sequence differs with the early entrance model, see Figure 3. After the investments of the leaders in stage 1 , the market entrance of the leaders is situated in stage 2. Thus followers invest (stage 3) after the market entrance of the leaders, therefore this setting is called late entrance. An important consequence of this change in sequence is that spillovers from the followers to the leaders are impossible. In stage 4, finally, the followers enter the market. The question is whether the tendencies of the early entrance game remain valid in this late entrance setting. To indicate the difference in spillovers between the early and the late entrance setting, the spillovers are here labelled by the symbol $\delta$. Thus, with symmetric spillovers, $\delta=\delta_{\mathrm{LL}}=\delta_{\mathrm{LF}}=\delta_{\mathrm{FF}}$

\section{Insert Figure III}

Comparing strategic investments of leaders and followers in the four games in the late entrance setting yields again similar results as in the early entrance setting. Some differences between the models of Figure 1 and 3 do appear however.

The comparison of the efforts of leaders and followers gives the following result. Followers may invest more than leaders. When leaders compete, higher investment incentives of followers are more likely when

\footnotetext{
${ }^{3}$ Exception: When $\mathrm{k}$ is high (e.g. $n=10$ and $k \geq 4$ ) and the leaders compete, producer surplus is higher with idea diffusion.
} 
- $\quad$ there is blue print diffusion to followers and leaders $\left(\delta_{\mathrm{LF}}=\delta_{\mathrm{LL}}=1\right)$ and

- when followers compete, their internal spillover is low $\left(\delta_{\mathrm{FF}}=1\right)$ or

- when followers cooperate, their internal spillover is high $\left(\delta_{\mathrm{FF}}=1\right)$.

With cooperating followers, followers tend to invest more than the leaders with

- $\quad$ blue print diffusion to followers $\left(\delta_{\mathrm{LF}}=1\right)$ with

- idea diffusion among the leaders $\left(\delta_{\mathrm{LL}}=0\right)$ or

- blue print among leaders $\left(\delta_{\mathrm{LL}}=1\right)$ with $\delta_{\mathrm{FF}}=0$ when followers compete or $\delta_{\mathrm{FF}}=1$ when followers cooperate

Comparing this result with (8) indicates that, in the late entrance setting, there are less spillover combinations leading to higher efforts of the followers.

Concerning the impact of cooperation with symmetric spillovers, the critical spillover $\delta^{\mathrm{LC}}$ is not exactly the same as in the early entrance game. However, its value is (very) close to $(n-k+1) /(n-k+2)$ and the small deviation is due to the lack of spillovers from followers to leaders. On the other hand, $\delta^{\mathrm{FC}}$ takes the same value as $\beta^{\mathrm{FC}}$ and is equal to $1 / 2$. Also with asymmetric spillovers, the critical value $\delta_{\mathrm{LL}}^{\mathrm{C}}$ depends again in a complex way on some of the other parameters of the model, i.e. $\delta_{\mathrm{LF}}, \delta_{\mathrm{FF}}$ and $\tau^{4}$. From this expression, we see that $\delta_{\mathrm{LL}}{ }^{\mathrm{C}}$ equals $1 / 2$ when $\delta_{\mathrm{LF}}$ is 0 . However, $\delta_{\mathrm{FF}}{ }^{\mathrm{C}}$ is always equal to $1 / 2$, which is always higher than the corresponding critical spillover in the early entrance setting. The results of the impact of cooperation on the profitability of leaders and followers are analogous as in the early entrance setting.

Furthermore, the welfare tendencies of the early entrance game with symmetric spillovers can almost be copied to the setting of the late entrance. With asymmetric spillovers, tendencies remain analogous; however, attention should be paid to the definition of small, intermediate and large (cf. table 4). Spillovers that are small in the late entrance setting can be labeled intermediate in the early entrance setting, by which the resulting welfare conclusions will be different. The next table summarizes the results of the static welfare analysis of the late entrance model.

${ }^{4} \delta_{L L}^{C}=\frac{1}{2} \times \frac{(n-k+1) \times(n-k) \times \delta_{L F} \times \tau-2 \times(n-k)+(n-k+1)^{2} \times \tau+2 \times(n-k-1)^{2} \times \delta_{L L} \times\left(1-\delta_{L L}\right)}{-2 \times(n-k)+(n-k+1)^{2} \times \tau+2 \times(n-k-1)^{2} \times \delta_{L L} \times\left(1-\delta_{L L}\right)}$ 
From table 8 , it is clear that welfare tendencies with symmetric spillovers are analogous to the early entrance setting, but note that there are no exceptions anymore.

Table 8. Comparison of static welfare for leader follower games with symmetric and asymmetric spillovers. The four games involve: $\mathrm{A}=(\mathrm{NL}, \mathrm{NF}), \mathrm{B}=(\mathrm{CL}, \mathrm{NF}), \mathrm{C}=(\mathrm{NL}, \mathrm{CF})$ and $\mathrm{D}=(\mathrm{CL}, \mathrm{CF})$, with $\mathrm{N}$ $=$ Nash, $\mathrm{C}=$ cooperation, $\mathrm{L}=$ leaders, $\mathrm{F}=$ followers.

\begin{tabular}{|l|l|l|}
\hline Symmetric spillover $\delta$ & $\begin{array}{l}\text { Asymmetric spillovers, } \\
0<\delta_{\mathrm{FF}}{ }^{\mathrm{C}}<\delta_{\mathrm{LL}}{ }^{\mathrm{C}}<1^{\circ}\end{array}$ & Ranking static welfare \\
in games A, B, C and D \\
$0 \leq \delta<0,5$ & Small: & A $>\mathrm{C}>\mathrm{B}>\mathrm{D}$ \\
\hline Small: & $0 \leq \delta_{\mathrm{FF}}<0,5$ & \\
\hline Intermediate: & $\begin{array}{l}\text { Intermediate: } \\
0,5<\delta<\delta_{\mathrm{LL}}^{\mathrm{LC}}<0,5\end{array}$ & $\mathrm{C}>\mathrm{A}>\mathrm{B}$ \\
& $0,5<\delta_{\mathrm{FF}}<\delta_{\mathrm{LL}}{ }^{\mathrm{C}}$ & $\mathrm{C}>\mathrm{D}>\mathrm{B}$ \\
\hline Large: & $0,5<\delta_{\mathrm{LL}}<\delta_{\mathrm{LL}}{ }^{\mathrm{C}}$ & \\
$\delta^{\mathrm{LC}}<\delta \leq 1$ & Large: & $\mathrm{D}>\mathrm{C}>\mathrm{B}>\mathrm{A}$ \\
& $\delta_{\mathrm{LL}}{ }^{\mathrm{C}}<\delta_{\mathrm{FF}} \leq 1$ & \\
& $\delta_{\mathrm{LL}}{ }^{\mathrm{C}}<\delta_{\mathrm{LL}} \leq 1$ & \\
\hline
\end{tabular}

\section{CONCLUSION}

This paper analyzed the strategic investments of leaders and followers in a four stage game with sequential investment decisions followed by sequential output decisions, given symmetric or asymmetric spillovers. Critical spillover levels drive the comparison of cooperative and competitive efforts and of leader and follower strategic investments. With symmetric spillovers the critical levels are often constants or simple functions of other parameters. But with asymmetry they tend to be related in complicated ways to the other characteristics of the games. 
Using extensive numerical simulations a number of tendencies could be obtained. They detail circumstances when followers will invest more and when cooperation of leaders, or of followers, or of leaders and of followers, stimulates efforts and improves on static welfare.

\section{LIST OF FIGURES}

Figure I: Early Entrance Setting

Figure II. Welfare in Early Entrance setting.

Figure III: Late Entrance Setting 


\section{FIGURES}

Figure I: Early Entrance Setting

The early entrance setting for $\mathrm{k}=2$ and $\mathrm{n}=5$. Extension to the general case of $1 \leq \mathrm{k}<\mathrm{n}$ is obvious. The spillover from followers to leaders $\beta_{\mathrm{FL}}$ is set equal to zero, except in the benchmark case of symmetric spillovers $\left(\beta_{\mathrm{LL}}=\beta_{\mathrm{LF}}=\beta_{\mathrm{FF}}=\beta_{\mathrm{FL}}=\beta\right)$.

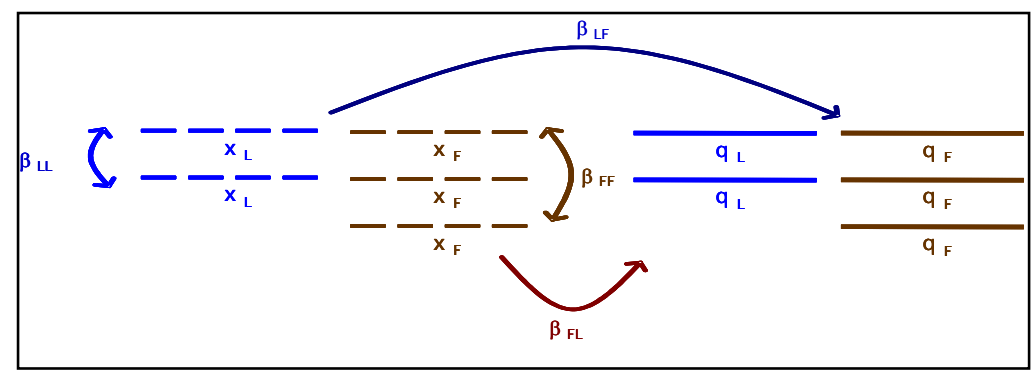

Figure II: Welfare in Early Entrance setting.

Welfare in function of the symmetric spillover $\beta$, for all four games in the early entrance setting.

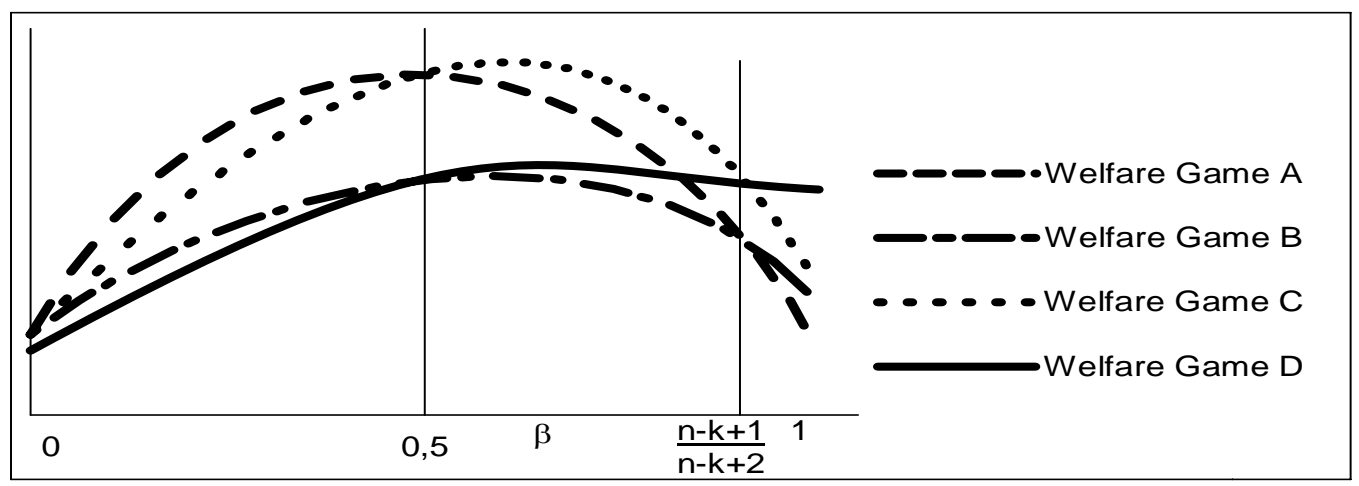

Figure III: Late Entrance Setting 
The late entrance setting for $\mathrm{k}=2$ and $\mathrm{n}=5$. Extension to the general case is obvious. There are no spillovers from followers to leaders in this four period setting. When spillovers are symmetric, $\delta_{\mathrm{LL}}=\delta_{\mathrm{LF}}=\delta_{\mathrm{FF}}=\delta$.

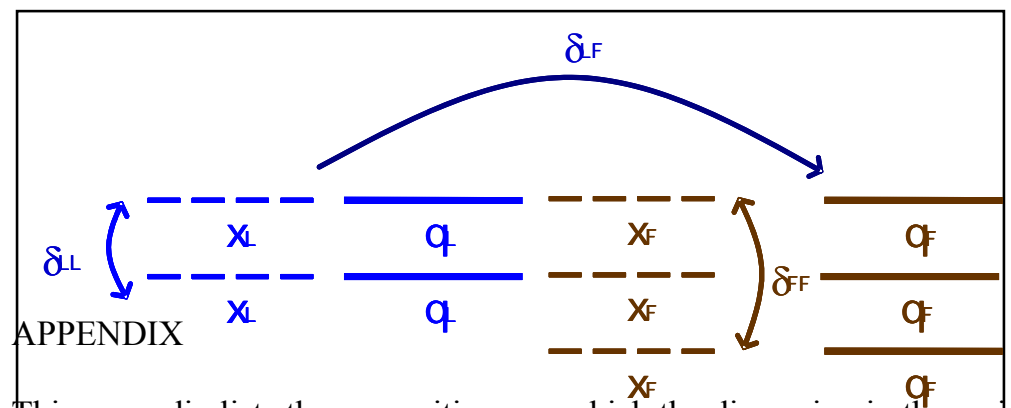

This appendix lists the propositions on which the diseussion in the main text is based. The early entrance setting means an industry composed of $\mathrm{n}$ firms, of which $\mathrm{k}$ are leading and $\mathrm{n}-\mathrm{k}$ are following, with four stage games detailed in the text. All these result were obtained through numerical simulations, a sample of which is available from the authors.

Proposition 1 compares efforts of leaders and followers. Proposition 2 through 5 summarize the effect of cooperation on strategic investments. The propositions 6 through 9 compare static welfare.

Proposition 1.

In an early entrance setting with asymmetric spillovers and competing or cooperating leaders and

followers, there exists, for each value of $\beta_{\mathrm{FL}}, \beta_{\mathrm{LL}}$ and $\beta_{\mathrm{FF}}$, a $\beta_{L F}^{e}$, for which (with $\mathrm{i}=1 \ldots \mathrm{k}$ and $\mathrm{j}=\mathrm{k}+1 \ldots \mathrm{n}$ ):

- if $\beta_{L F}<\beta_{L F}^{e}$, then $x_{L, i}>x_{F, j}$;

- if $\beta_{L F}=\beta_{L F}^{e}$, then $x_{L, i}=x_{F, j}$;

- if $\beta_{L F}>\beta_{L F}^{e}$, then $x_{L, i}<x_{F, j}$.

The exact value of this $\beta_{L F}^{e}$ is different across the four games A, B, C, and D considered. It is possible that leaders always invest more than followers $\left(x_{L, i}>x_{F, j}\right)$. In those cases $\beta_{L F}^{e}$ is higher than 1 . It is also possible that some spillover combinations always lead to higher investments of the followers $\left(x_{L, i}<x_{F, j}\right)$, which could be interpreted as $\beta_{L F}^{e}$ taking values lower than 0. 
Proposition 2.

In an early entrance setting with symmetric spillovers and competing (cooperating) followers, there exists a critical spillover, $\beta^{\mathrm{LC}}$, for which:

- if $\beta<\beta^{\mathrm{LC}}$, then $x_{L}^{N L, N F}>x_{L}^{C L, N F}\left(x_{L}^{N L, C F}>x_{L}^{C L, C F}\right)$;

- if $\beta=\beta^{\mathrm{LC}}$, then $x_{L}^{N L, N F}=x_{L}^{C L, N F}\left(x_{L}^{N L, C F}=x_{L}^{C L, C F}\right)$;

- if $\beta>\beta^{\mathrm{LC}}$, then $x_{L}^{N L, N F}<x_{L}^{C L, N F}\left(x_{L}^{N L, C F}<x_{L}^{C L, C F}\right)$.

The value of $\beta^{\mathrm{LC}}$ is equal to $\frac{n-k+1}{n-k+2}$.

Proposition 3.

Given an early entrance setting with symmetric spillovers and competing (cooperating) leaders, there exists a critical spillover, $\beta^{\mathrm{FC}}$, for which:

- if $\beta<\beta^{\mathrm{FC}}$, then $x_{F}^{N L, N F}>x_{F}^{N L, C F}\left(x_{F}^{C L, N F}>x_{F}^{C L, C F}\right)$;

- if $\beta=\beta^{\mathrm{FC}}$, then $x_{F}^{N L, N F}=x_{F}^{N L, C F}\left(x_{F}^{C L, N F}=x_{F}^{C L, C F}\right)$;

- if $\beta>\beta^{\mathrm{FC}}$, then $x_{F}^{N L, N F}<x_{F}^{N L, C F}\left(x_{F}^{C L, N F}>x_{F}^{C L, C F}\right)$.

The value of $\beta^{\mathrm{FC}}$ is equal to $1 / 2$.

Proposition 4.

In an early entrance setting with asymmetric spillovers and competing (cooperating) followers, there exists a critical leader-specific spillover, $\beta_{\mathrm{LL}}{ }^{\mathrm{C}}$, for which:

- if $\beta_{\mathrm{LL}}<\beta_{\mathrm{LL}}{ }^{\mathrm{C}}$, then $x_{L}^{N L, N F}>x_{L}^{C L, N F}\left(x_{L}^{N L, C F}>x_{L}^{C L, C F}\right)$;

- if $\beta_{\mathrm{LL}}=\beta_{\mathrm{LL}}{ }^{\mathrm{C}}$, then $x_{L}^{N L, N F}=x_{L}^{C L, N F}\left(x_{L}^{N L, C F}=x_{L}^{C L, C F}\right)$;

- if $\beta_{\mathrm{LL}}>\beta_{\mathrm{LL}}{ }^{\mathrm{C}}$, then $x_{L}^{N L, N F}<x_{L}^{C L, N F}\left(x_{L}^{N L, C F}<x_{L}^{C L, C F}\right)$.

The value of $\beta_{\mathrm{LL}}{ }^{\mathrm{C}}$ is, however, different according to whether followers compete or cooperate.

Proposition 5. 
Given an industry consisting of $\mathrm{n}$ firms, of which $\mathrm{k}$ are leading while the remaining $\mathrm{n}-\mathrm{k}$ firms are following, asymmetric spillovers and competing (cooperating) leaders, there exists a critical followerspecific spillover, $\beta_{\mathrm{LL}}{ }^{\mathrm{C}}$, for which:

- if $\beta_{\mathrm{FF}}<\beta_{\mathrm{FF}}^{\mathrm{C}}$, then $x_{F}^{N L, N F}>x_{F}^{N L, C F}\left(x_{F}^{C L, N F}>x_{F}^{C L, C F}\right)$;

- if $\beta_{\mathrm{FF}}=\beta_{\mathrm{FF}}^{\mathrm{C}}$, then $x_{F}^{N L, N F}=x_{F}^{N L, C F}\left(x_{F}^{C L, N F}=x_{F}^{C L, C F}\right)$;

- if $\beta_{\mathrm{FF}}>\beta_{\mathrm{FF}}{ }^{\mathrm{C}}$, then $x_{F}^{N L, N F}<x_{F}^{N L, C F}\left(x_{F}^{C L, N F}<x_{F}^{C L, C F}\right)$.

The value of $\beta_{\mathrm{LL}}{ }^{\mathrm{C}}$ is the same, regardless if leaders cooperate or not. The value of $\beta_{\mathrm{FF}}{ }^{\mathrm{C}}$ is equal to $\frac{1}{2+(n+1) k-k^{2}}$.

The following 4 propositions compare static welfare in the four games $A=(N L, N F), B=(C L, N F), C=$ $(\mathrm{NL}, \mathrm{CF})$ and $\mathrm{D}=(\mathrm{CL}, \mathrm{CF})$, with $\mathrm{N}=$ Nash, $\mathrm{C}=$ cooperation, $\mathrm{L}=$ leaders, $\mathrm{F}=$ followers.

\section{Proposition 6.}

Given an early entrance setting with symmetric spillovers and competing (cooperating) leaders, there exists a critical spillover, $\beta^{\mathrm{FC}}$, for which:

- if $\beta<\beta^{\mathrm{FC}}$, then $S W^{N L, N F}>S W^{N L, C F}\left(S W^{C L, N F}>S W^{C L, C F}\right)$;

- if $\beta=\beta^{\mathrm{FC}}$, then $S W^{N L, N F}=S W^{N L, C F}\left(S W^{C L, N F}=S W^{C L, C F}\right)$;

- if $\beta>\beta^{\mathrm{FC}}$, then $S W^{N L, N F}<S W^{N L, C F}\left(S W^{C L, N F}<S W^{C L, C F}\right)$.

The value of $\beta^{\mathrm{FC}}$ is equal to $1 / 2$.

\section{Proposition 7.}

In an early entrance setting with symmetric spillovers and competing (cooperating) followers, there exists a critical spillover, $\beta^{*}$, for which:

$$
\begin{aligned}
& \text { - if } \beta_{\mathrm{LL}}<\beta^{\mathrm{LC}} \text {, then } S W^{N L, N F}>S W^{C L, N F}\left(S W^{N L, C F}>S W^{C L, C F}\right) ; \\
& \text { - if } \beta_{\mathrm{LL}}=\beta^{\mathrm{LC}} \text {, then } S W^{N L, N F}=S W^{C L, N F}\left(S W^{N L, C F}=S W^{C L, C F}\right) ; \\
& \text { - if } \beta_{\mathrm{LL}}>\beta^{\mathrm{LC}} \text {, then } S W^{N L, N F}<S W^{C L, N F}\left(S W^{N L, C F}<S W^{C L, C F}\right)
\end{aligned}
$$


The value of $\beta_{\mathrm{LL}}^{\mathrm{C}}$ is equal to $\frac{n-k+1}{n-k+2}$.

Proposition 8.

In an early entrance setting with asymmetric spillovers and competing (cooperating) leaders, there exists a critical follower-specific spillover, $\beta_{\mathrm{FF}}{ }^{\mathrm{C}}$, for which:

- if $\beta_{\mathrm{FF}}<\beta_{\mathrm{FF}}{ }^{\mathrm{C}}$, then $S W^{N L, N F}>S W^{N L, C F}\left(S W^{C L, N F}>S W^{C L, C F}\right)$;

- if $\beta_{\mathrm{FF}}=\beta_{\mathrm{FF}}^{\mathrm{C}}$, then $S W^{N L, N F}=S W^{N L, C F}\left(S W^{C L, N F}=S W^{C L, C F}\right)$;

- if $\beta_{\mathrm{FF}}>\beta_{\mathrm{FF}}$, then $S W^{N L, N F}<S W^{N L, C F}\left(S W^{C L, N F}<S W^{C L, C F}\right)$.

The value of $\beta_{\mathrm{FF}}{ }^{\mathrm{C}}$ is the same, regardless if leaders cooperate or not. The value of $\beta_{\mathrm{FF}}{ }^{\mathrm{C}}$ is equal to $\frac{1+\beta_{F L}(n+1) k-\beta_{F L} k^{2}}{2+(n+1) k-k^{2}}$

Proposition 9.

In an early entrance setting with asymmetric spillovers and competing (cooperating) followers, there exists a critical leader-specific spillover, $\beta_{\mathrm{LL}}{ }^{\mathrm{C}}$, for which:

- if $\beta_{\mathrm{LL}}<\beta_{\mathrm{LL}}{ }^{\mathrm{C}}$, then $S W^{N L, N F}>S W^{C L, N F}\left(S W^{N L, C F}>S W^{C L, C F}\right)$;

- if $\beta_{\mathrm{LL}}=\beta_{\mathrm{LL}}{ }^{\mathrm{C}}$, then $S W^{N L, N F}=S W^{C L, N F}\left(S W^{N L, C F}=S W^{C L, C F}\right)$;

- if $\beta_{\mathrm{LL}}>\beta_{\mathrm{LL}}{ }^{\mathrm{C}}$, then $S W^{N L, N F}<S W^{C L, N F}\left(S W^{N L, C F}<S W^{C L, C F}\right)$

The value of $\beta_{\mathrm{LL}}{ }^{\mathrm{C}}$ is different according to whether followers compete or cooperate. 


\section{REFERENCES}

Amir, M, R. Amir, J. Jin (2000) Sequencing R\&D in a Two-Period Duopoly with Spillovers. Economic Theory 15(2), 297-317.

Atallah, G. (2005) R\&D Cooperation with Asymmetric Spillovers. Canadian Journal of Economics 38(3), 919-936.

Czarnitzki, D. and K. Kraft (2004) An Empirical Test of the Asymmetric Models on Innovative Activity: Who Invests More into R\&D, the Incumbent or the Challenger? Journal of Economic Behavior \& Organization 54, 153-173.

Crampes, C. and C. Langinier. C. (2003) Following the Follower in the Innovation Game. IDEI Working Papers, $n^{\circ} 216$, Institut d'Économie Industrielle (IDEI), Toulouse.

d'Aspremont, C. and A. Jacquemin (1988) Cooperative and Noncooperative R\&D in Duopoly with Spillovers. American Economic Review 78(8) pp. 1133-1137.

Daughety, A.F. (1990) Beneficial Concentration. American Economic Review, 80(5), 1321-1237.

De Bondt, R. and R. Veugelers (1991) Strategic Investment with Spillovers. European Journal of Political Economy, 7, 345-366. 
De Bondt, R. and I. Henriques (1995). Strategic Investments with Asymmetric Spillovers. Canadian Journal of Economics, 28(3), 656-674.

De Bondt, R. and C. Wu (1997) Research joint venture cartels and welfare, in: J. Poyago-Theotoky, ed., R\&D cooperation: theory and practice (Macmillan, London).

De Bondt, R. (1997) Spillovers and Innovative Activities. International Journal of Industrial Organization 15(1), 1-28.

Ulirch, D. (2003) An R\&D Race with Knowledge Accumulation. RAND Journal of Economics, 34(1), $20-42$.

Diamond, J. (1997) Guns, Germs, and Steel. New York, W.W. Norton \& Company.

Etro, F. (2004) Innovation by Leaders. Economic Journal, 114, 281-303.

Goel, R.A. (1990) Innovation, Market Structure, and Welfare: A Stackelberg Model. Quarterly Review of Economics and Business, 30, 40-53.

Halmenschlager, C. (2004). R\&D-Cooperating Laggards versus a Technological Leader. Economics of Innovation and New Technology, 13(8), 717-732.

Kamien, M.I., E. Muller and I. Zang. (1992) Research Joint Ventures and R\&D Cartels. The American Economic Review, 82(5), 1293-1306.

Kamien, M.I. and I. Zang, (1990) The Limits of Monopolization through Acquisition. Quarterly Journal of Economics, 105, 465-499.

Motta, M. (2004) Competition Policy. Theory and Practice. Cambridge, Cambridge University Press. 
Reinganum J.F. (1985) A Two-Stage Model of Research and Development with Endogenous SecondMover Advantages, International Journal of Industrial Organization, 3, 275-92.

Sena, V. (2004) The Return of the Prince of Denmark: A Survey on Recent Developments in the Economics of Innovation. The Economic Journal, 114 (496), 312-332.

Schilling, M.A. (2003) Technological Leapfrogging: Lessons from the U.S. Video Game Console Industry. California Management Review, 45, 6-32.

Schnaars, S.P. (1994) Managing Imitation Strategies. New York, The Free Press.

The Economist (2005) Leo Sternbach. Leo Sternbach, inventor of Valium, died on September $28^{\text {th }}$, aged 97. 15 October, 90 . 